\title{
Sequencing, de novo assembly and annotation of the genome of the scleractinian coral, Pocillopora acuta
}

\author{
Jeremie Vidal-Dupiol $^{1 *}$, Cristian Chaparro ${ }^{2}$, Marine Pratlong ${ }^{3,4}$, Pierre Pontarotti ${ }^{3,5}$, Christoph \\ Grunau $^{2}$, Guillaume Mitta ${ }^{2}$
}

1 IHPE, Univ. Montpellier, CNRS, Ifremer, Univ. Perpignan Via Domitia, Montpellier France 2 IHPE, Univ. Montpellier, CNRS, Ifremer, Univ. Perpignan Via Domitia, Perpignan France 3 Aix Marseille Univ,IRD, APHM, Microbe, Evolution, PHylogénie, Infection IHU Méditerranée Infection, Marseille France. Evolutionary Biology team.

4 Aix-Marseille Université, Avignon Université, CNRS, IRD, IMBE, Marseille, France

5 SNC5039 CNRS 19-21 Boulevard Jean Moulin 13005 Marseille

*Corresponding author: jeremie.vidal.dupiol@ifremer.fr

\begin{abstract}
Coral reefs are the most divers marine ecosystem. However, under the pressure of global changes and anthropogenic disturbances corals and coral reefs are declining worldwide. In order to better predict and understand the future of these organisms all the tools of modern biology are needed today. However, many NGS based approaches are not feasible in corals because of the lack of reference genomes. Therefore we have sequenced, de novo assembled, and annotated, the draft genome of one of the most studied coral species, Pocillopora acuta (ex damicornis). The sequencing strategy was based on four libraries with complementary insert size and sequencing depth (180pb, 100x; 3Kb, 25x; 8kb, 12x and $20 \mathrm{~kb}, 12 \mathrm{x})$. The de novo assembly was performed with Platanus (352 Mb; 25,553 scaffolds; N50 171,375 bp). 36,140 genes were annotated by RNA-seq data and 64,558 by AUGUSTUS (Hidden-Markov model). Gene functions were predicted through Blast and orthology based approaches. This new genomic resource will enable the development of a large array of genome wide studies but also shows that the de novo assembly of a coral genome is now technically feasible and economically realistic.
\end{abstract}




\section{Introduction}

Coral reefs are the most divers marine ecosystem and the second one in terms of diversity after tropical rain forests (Knowlton et al. 2010). In addition to this ecological importance, it provides many ecosystem services, such as a direct access to food and economic-resources through fishing and tourisms (Done et al. 1996, Bryant et al. 1998). The physical and biological support of this ecosystem relies exclusively on one type of organisms, the hermatypic scleractinian coral. Worryingly, these sessile, colonial and symbiotic species are today threatened by an increasing number of various anthropogenic and natural disturbances (Hughes et al. 2003), inducing since the 80's a worldwide decline of this ecosystem (Bellwood et al. 2004). As a consequence the research performed on these biological models has exponentially increased on all aspect of their biology.

Today, most methods studying variations at the transcriptomic, genetic or epigenetic level rely on next generation sequencing. The generalization of these approaches in model organisms such as in the mouse, drosophila or baker's yeast has made it possible to achieve tremendous insights into the biology of these organisms leading to advances in numerous scientific domains (Koboldt et al. 2013). With the cost reduction of the NGS approach, this was also promised but is not yet fulfilled for non-model organisms because of the lack of reference genomes in many phyla or functionnal group. Among the anthozoa, reference genomes are available for the laboratory models Nematostella vectensis (Putnam et al. 2007) and Aiptasia sp. (Baumgarten et al. 2015). However, there is still few reference genomes for the ecologically important hermatypic corals. To date four species were sequenced and assembled: Acropora digitifera (Shinzato et al. 2011), Pocillopora damicornis (Cunning et al. 2018), Stylophora pistillata (Voolstra et al. 2017) and Orbicela faveolata (Prada et al. 2016). However, others are needed to widen the research effort on the future of biodiversity and corals adaptability to global changes.

Among the most studied coral is Pocillopora acuta (previously considered as a synonymous of $P$. damicornis until 2014 (Veron and Pichon 1976)). P. acuta is encountered on fringing reefs and sheltered areas in the entire Indopacific ocean (Veron 2000). P. acuta is also known to be very sensitive to many natural disturbances including coral bleaching (i.e. the symbiosis breakdown between the coral host and its micro-algae endosymbiont) (Loya et al. 2001) and diseases (Ben-Haim and Rosenberg 2002, Luna et al. 2007). It shows relatively good capacities of acclimatization to controlled condition and thus can be maintained in 
aquaria for decades where it present the advantage to be a fast growing species. These various features have led many scientists to use this coral as a model in a large variety of scientific fields such as population genetics (Adjeroud et al. 2013, Combosch and Vollmer 2015), integrative biology (Vidal-Dupiol et al. 2009, Vidal-Dupiol et al. 2011a), functional genomics (Traylor-Knowles et al. 2011), global changes impact (Vidal-Dupiol et al. 2013, Vidal-Dupiol et al. 2014), transgenerational acclimation (Putnam and Gates 2015), coral diseases (BenHaim Rozenblat and Rosenberg 2004, Vidal-Dupiol et al. 2011b), physiology (Richmond 1987, Stimson 1997) and host microbiota interactions (Bourne and Munn 2005) etc. which makes $P$. acuta a major scleractinian coral model.

Although transcriptomic resources are available (Traylor-Knowles et al. 2011, VidalDupiol et al. 2011b) a reference genome for $P$. acuta is still lacking but could enable substantial advances in the understanding of various aspects of coral biology, ecology and evolution. In this context, the aim of the present study is to provide to the scientific community the draft genome sequence and annotation of $P$. acuta. To address this objective, the DNA from a single colony was sequenced using the Illumina technology and de novo assembled using Platanus assembler (Kajitani et al. 2014). The annotation of genes and repeats was performed. Gene prediction was conducted; firstly by an experimental annotation using previously published RNA-seq libraries and secondly, by an ab initio prediction based on a Hidden-Markov models. Finally, the putative function of each gene and its transcripts were identified by database searches and by an orthology based approach.

\section{Material and methods}

\section{Biological material and DNA extraction}

The P. acuta (Linnaeus, 1758) isolate used in this study was sampled in Lombok, Indonesia (Indonesian CITES Management Authority, CITES number 06832/VI/SATS/LN/2001-E; France Direction de l'Environnement, CITES number 06832/VI/SATS/LN/2001-I) and has been maintained in aquaria since the year 2001. Previously assigned to Pocillopora damicornis this isolate was reassigned to P. acuta. This assignation was based on the 840 based pair sequence of the ORF marker that enable to separate P. acuta and P. damicornis (Schmidt-Roach et al. 2014). 
In order to avoid contaminations by the zooxanthellae for genome assembly $P$. acuta mini colonies ( $\sim 7 \mathrm{~cm}$ high, $\sim 6 \mathrm{~cm}$ diameter) used for DNA extraction were subjected to a menthol treatment inducing bleaching. Briefly, the colonies were placed in a four litter tank filled with seawater. Water motion was created using a submerged water pump $(100 \mathrm{~L} / \mathrm{h})$, temperature was maintained at $27^{\circ} \mathrm{C}$ and light adjusted to $75 \mu \mathrm{mol} / \mathrm{m}^{2} / \mathrm{s}$ (PAR). The protocol for the menthol treatment was adapted from previous work (Wang et al. 2012). The first day, the corals were subjected to a concentration of menthol of $0.58 \mathrm{mmol} / \mathrm{L}$ for $6 \mathrm{~h}$. After this exposure they were transferred to the coral nursery for a $18 \mathrm{~h}$ recovery period. During the second day, the same protocol was applied (menthol treatment and recovery step). The third day, the coral were exposed again to the same treatment but only until the polyps were closed. Once achieved the corals were placed in the coral nursery for recovery while at the same time they lose zooxanthellae. This last step typically takes four to five days.

For DNA extraction, coral tissues of one bleached mini colony $(\sim 7 \mathrm{~cm} \mathrm{high,} \sim 6 \mathrm{~cm}$ diameter) were harvested using an airpic in $50 \mathrm{~mL}$ of tissue extraction buffer (1M sucrose; $0.05 \mathrm{mM}$ EDTA; $\left.4^{\circ} \mathrm{C}\right)$. Then, the extract was centrifuged $10 \mathrm{~min}$ at $3000 \mathrm{~g}\left(4^{\circ} \mathrm{C}\right)$ and the pellet was resuspended in the G2 buffer of the QIAGEN Genomic DNA kit. The rest of the protocol was performed according to the manufacturer's instructions with the 100/G Genomic-tip. DNA quantity and quality were assessed by spectrophotometry (nanodrop), fluorescence (Qbit) and 0.5\% agarose gel electrophoresis.

\section{Library preparation and sequencing}

In order to facilitate the de novo assembly of the $P$. acuta genome, four different libraries were constructed and sequenced. Sequencing was performed on an Illumina Hiseq 2000 producing 100 bp paired-end reads. The first library was a shotgun (SG) library with an expected average insert size of $180 \mathrm{bp}$. It was sequenced at an estimated genome coverage of 100X. The second one was a long jumping distance (LJD) library with an average insert size of $3000 \mathrm{bp}$. It was sequenced for an estimated genome coverage of $25 \mathrm{X}$. The two last one were LJD libraries with an expected average insert size of 8 and $20 \mathrm{~kb}$, respectively. The sequencing coverage was estimated at $12 \mathrm{X}$. Sequencing and library preparation were performed by the Eurofin company.

De novo genome assembly

A stringent cleaning pipeline of the raw reads was applied to the four libraries. First, all reads of the four libraries were filtered in function of their quality. Only reads displaying a 
Phred quality score $>30$ for $95 \%$ of its bases were kept for the analysis (FASTX-Toolkit). Secondly, the remaining reads were cleaned from any trace of adaptor using cutadapt program (Martin 2011). Thirdly, reads were interlaced/de-interlaced to separate singleton from paired reads and finally the reads from the SG library were subjected to a correction step using ErrorCorrection program from the SOAPdenovo2 package (Luo et al. 2012).

For the de novo assembly of $P$. acuta genome we used the multiple kmer assembler Platanus (Kajitani et al. 2014). For the contiguing step, only the paired read of the SG library were used. For scaffolding, the reads of all libraries were sequentially used from the shortest to the longest insert size (SG 180pb, LJD 3kb, LJD 8kb, LJD $20 \mathrm{~kb}$ ). In a last step, gaps generated during scaffolding were closed using the paired reads of the SG libraries using the gap closer program included in the Platanus package. Once completed, the assembly quality was assessed by classical metrics (total assembly length, longest scaffold, N50 etc.) compiled in the program QUAST (Gurevich et al. 2013). In order to provide a functional validation of the assembly this quality assessment was also performed using the program CEGMA that looks for the presence of the 248 most conserved core eukaryotic proteins in the assembly (Parra et al. 2007). All scripts and parameters used in command line during the bioinformatics treatments are summarized in supplementary data 1, other tools were run on a local Galaxy instance.

\section{Structural annotation}

As a first approach for genome annotation, exon/intron structures of genes were determined using RNA-seq data (experimental approach) previously published (Vidal-Dupiol et al. 2013, Vidal-Dupiol et al. 2014). The cleaned paired reads from our previous work were mapped against the scaffolds with a length above $5 \mathrm{~kb}$ using TopHat2 (Trapnell et al. 2009). All parameters were used with the default setting except for the mean and the standard deviation of the inner distance between pairs that were adapted to each specific library. Once mapped, the BAM file output obtained for each RNA-seq library was used to assemble the transcripts defined by TopHat2. This was done with Cufflinks with default parameters (Trapnell et al. 2010). Finally, all the transcript assembly generated (one per mapped RNAseq library) were merged with Cuffmerge (Trapnell et al. 2010) using the default parameters.

Because our RNA-seq libraries potentially did not cover all putative transcripts in the genome, we performed as a second approach an ab initio gene prediction. This step was done using the AUGUSTUS web server (Stanke and Waack 2003) with the genome assembly filtered for scaffolds $\geq 5 \mathrm{~kb}$ and the Cuffmerge transcriptome as input file for the training and 
prediction steps. Genes were predicted on both strands with the option "predict any number of genes".

\section{Functional annotation}

In order to attribute a putative function to a maximum of the predicted transcripts but with the lowest probability of wrong annotation we applied two independent methods. The longest ORF of each putative transcripts was found using getorf (Rice et al. 2000), and the ones longer than 100 amino acids were selected for annotation. Then we used orthoMCL (Li et al. 2003) to identify potential orthologous sequences between our predicted ORF and; very well annotated genomes (Homo sapiens (Venter et al. 2001), Mus musculus (Chinwalla et al. 2002), Caenorhabditis elegans (Consortium 1998), Danio rerio (Howe et al. 2013), Drosophila melanogaster (Adams et al. 2000), Saccharomyces cerevisiae (Mewes et al. 1997) and Strongylocentrotus purpuratus (Sodergren et al. 2006)); or with a biological and an evolutionary interest with regard to the phylogenetic position of our organism (the cnidarians Acropora digitifera (Shinzato et al. 2011), Hydra magnipapillata (Chapman et al. 2010) and Nematostella vectensis (Putnam et al. 2007), the coral symbiont Symbiodinium minutum (Shoguchi et al. 2013) and the sponge Amphimedon queenslandica (Srivastava et al. 2010)). Orthology was considered significant when the $e$-value obtained was lower than $10^{-5}$. In this case and when available, the annotation of the ortholog(s) was transferred to the $P$. acuta sequence. In parallel to this approach we used Blast2GO (Conesa et al. 2005) version 2.4.2 to perform a semi-automated functional annotation of all putative transcripts using a set of similarity search tools (Conesa et al. 2005) : i) an initial annotation with BLASTX (against the non redundant NCBI database; $e$-value at $1 \times 10^{-3}$ ); ii) a protein domain search using InterProscan; iii) an enzyme annotation using the Kyoto Encyclopedia of Genes and Genomes (Kanehisa and Goto 2000) (KEGG) enzyme database; and iv) assignment of a Gene Ontology term (Ashburner et al. 2000).

\section{Repeats annotation}

Identification of the transposable elements (TEs) from the SINE family was performed as described previously (Baucom et al. 2009). Briefly, clustering was done by aligning candidates and manually extracting the families which were realigned and borders identified when possible. For the annotation of other TEs, the search using RepeatMasker (TarailoGraovac and Chen 2009) and the Repbase (Jurka et al. 2005) library on the assembled scaffolds did not yield any positive results. We therefore opted for another strategy which 
consists on recuperating all the reads that do not align to the assembled scaffolds using samtools (Li et al. 2009) and assemble them using RepArk (Koch et al. 2014) into contigs which will be searched for signatures of TEs. The RepeatMasker/Repbase combination did not give any results on the assembled contigs, therefore, we used RepeatModeler (Smit and Hubley 2010) to create a specific repeat library for the assembled contigs and used that library with RepeatMasker to search for TEs.

\section{Contamination level and genome heterozygosis}

In order to evaluate the level of contamination by Symbiodinium sp. DNA that would be co-extracted with the coral DNA, we mapped the reads from the SG library on the genome of S. kawagutii (Lin et al. 2015) and S. minutum (Shoguchi et al. 2013). This was done with bowtie 2 in single-end and sensitive end to end modes (Langmead and Salzberg 2012). In a second step, potential PCR duplicates generated during the amplification step of the gDNAseq library preparation were removed using RmDup from the Sam tools package ( $\mathrm{Li}$ et al. 2009) to decrease artefactual redundancy.

In order to evaluate the level of heterozygosis of the reference genome the raw reads of the SG library were mapped with bowtie 2 on the $P$. acuta assembly. This was done in single end and sensitive end to end mode and as previously, PCR duplicates were removed with RmDup. Then, unique hits were filtered and used as input for variant calling using Varscan2 with default parameters (Koboldt et al. 2012).

\section{Results and Discussion}

\section{Sequencing and de novo assembly}

To enable the development of studies at the genome wide level and to strengthen the position of Pocillopora acuta as a coral model we sequenced and de novo assembled its genome. The sequencing strategy was based on 4 libraries with complementary insert sizes and sequencing depths (Table 1). The shotgun library (insert size $180 \mathrm{pb}$ ) yielded 237,589,976 paired reads of $100 \mathrm{bp}$ each with an average Q score of 36.45 (93.71\%>Q30). The corresponding 47,517 $\mathrm{Mb}$ produced correspond to an estimated genome coverage of 146X. The $3 \mathrm{~kb}$ LJD library has a measured average insert size of 2,479 bp. The sequencing yielded $109,242,128$ paired read of $100 \mathrm{bp}$ each with an average Q score of 32.31 (81.79\%>Q30) this corresponds to 21,848 Mbp (genome coverage $67 \mathrm{x}$ ). The $8 \mathrm{~kb}$ LJD library has a measured average insert size of 7,825 bp. The sequencing yielded 44,399,583 paired read of $100 \mathrm{bp}$ each with an average Qvalue of $31.98(80.56 \%>$ Q30) which corresponds to $8,880 \mathrm{Mbp}$ 
(genome coverage 27). The $20 \mathrm{~kb}$ LJD library has a measured average insert size of 32,325 bp. The sequencing yielded 99,813,316 paired read of $100 \mathrm{bp}$ each with an average Qvalue of 30.76 (77.73\%>Q30) which corresponds to 19,963 Mbp (genome coverage $61 \mathrm{x}$ ). In order to decrease the complexity of the dataset, the raw reads were quality filtered at Q30 for $90 \%$ of the read lenght, all remaining traces of adaptor were removed, and finally, sequencing error were corrected. Singleton were filtered and excluded from assembly.

The processed paired-reads were used as input for de novo assembly with Platanus assembler (contiging, scaffolding and gap closing). The assembly has resulted in 25,553 scaffolds greater than $1,000 \mathrm{bp}$ and a N50 of 171,375 bp (the main assembly quality statistics are summarized in the Table 2). The longest scaffold reached 1,296,445 bp and the overall assembly is only $8 \%$ longer than the predicted genome size (352 Mb vs $325 \mathrm{Mb}$ ). These metrics are in the same order of magnitude than those classically obtained for other anthozoans (Putnam et al. 2007, Shinzato et al. 2011, Baumgarten et al. 2015). Considering the genome size, our prediction and assembly results stay in the anthozoa range delineated by Aiptasia sp. (the smallest; $260 \mathrm{Mb}$ ) and Stylophora pistillata (the largest; $434 \mathrm{Mb}$ ) genome (Baumgarten et al. 2015, Voolstra et al. 2017).

The GC\% was equal to $37.84 \%$ and its distribution was unimodal. Since the GC \% of anthozoa is around 37-39\% (Shinzato et al. 2011) and around 44-46\% in Symbiodinium sp. (Shoguchi et al. 2013, Lin et al. 2015) our results suggest a very low level of contamination by Symbiodinium DNA in our assembly (Sabourault et al. 2009). This very low level of contamination was confirmed through the mapping of the reads constituting the SG library on the S. kawagutii and S. minutum genome (Shoguchi et al. 2013, Lin et al. 2015). Indeed, only $0.02 \%$ and $0.03 \%$ of these reads were mapped on the genomes of S. kawagutii and S. minutum respectively. This results is strengthen by the very low number of contigs (one contig) included in an orthologs group containing Symbiodinium sequences only. These results confirmed that the menthol treatment was very efficient to induce a complete bleaching of $P$. acuta (Wang et al. 2012).

Finally, in order to evaluate the biological significance of this assembly we looked for the presence of 248 ultra-conserved core eukaryotic gene (COG) with the CEGMA package (Parra et al. 2007). In total, 84\% of these COG were found in full length, and this number reach $93 \%$ when partial length similarities are included, showing the completeness of our assembly. These results are in the upper part of the range of values classically obtained from a de novo draft genome assembly performed with Illumina reads. For example, the draft 
genomes of the arthropods Sarcoptes scabie var. hominis and var. suis contained $98.79 \%$ of the 248 COG (Mofiz et al. 2016) while the draft genome of another arthropods, the chinese mitten crab Eriocheir sinensis contained $66.9 \%$ of these genes (Song et al. 2016).

\section{Structural and functional annotation}

We had based this structural and functional annotation on experimental (RNA-seq) and $a b$ initio approaches (Hidden-Markov model). Because these two approaches do not reach the same level of confidence we decided to keep the results of these two strategies separated. This will enable the users of these data to choose the experimental and/or ab initio gene predictions in function of the scientific question they will investigate.

As a first approach, genes were predicted using experimental data previously obtained. These RNA-seq libraries were chosen in order to cover a large range of physiological condition and include the response to the exposure to normal and high temperatures, virulent and non-virulent bacteria and acidification (Vidal-Dupiol et al. 2013, Vidal-Dupiol et al. 2014, Vidal-Dupiol et al. submitted). The paired reads of these libraries were used to predict gene and exon/intron structures on scaffolds with a size above or equal to $5 \mathrm{~kb}$. This approaches has predicted 36,140 genes encoding 63,181 alternatively spliced transcripts (Table 3). These predicted transcripts were then used to train AUGUSTUS (Hidden-Markov model) for the $a b$ initio gene prediction that had resulted in the identification of 64,558 predicted-genes encoding 79,506 alternatively spliced transcripts. The number of predicted genes using the experimental data is slightly higher to what was found for the two other sequenced symbiotic anthozoan (Shinzato et al. 2011, Baumgarten et al. 2015, Prada et al. 2016, Voolstra et al. 2017, Cunning et al. 2018). However the number of putative transcripts encoded by these genes are in agreement with what was classically obtained in Anthozoan transcriptome assembly (Meyer et al. 2009, Traylor-Knowles et al. 2011, Lehnert et al. 2012, Moya et al. 2012, Vidal-Dupiol et al. 2013, Shinzato et al. 2014, Kitchen et al. 2015). The differences between the number of gene predicted by the experimental and the $a b$ initio approaches may result from difficulties encountered by AUGUSTUS rather than by TopHat2. Indeed, the mean exon length is $30 \%$ lower in the ab initio approach and this may result in an increasing gene number due to gene fragmentation. This hypothesis is confirmed by CEGMA that shows that the completeness of the transcriptome issued from the $a b$ initio prediction is low with $56 \%$ of the 248 CEGs founds while $93 \%$ were found with the transcriptome generated by the experimental approach. In addition $a b$ initio approaches are known to annotate some false genes such as pseudogenes and nonfunctional duplicated genes. However, 
both predictions can be usefull since genes specifically involved in some developmental process, larval stage, etc. may be represented in the ab initio annotation only, because genes pertaining to these physiological states were not found with the experimental annotation.

The functional annotation was done using Blast2GO (Conesa et al. 2005) on the transcripts predicted from the RNA-seq and ab initio approaches, separately (Table 3). The BlastX performed on the non-redundant NCBI database returned the following results for the transcripts issued from the RNA-seq and ab initio approaches, respectively: i) $77.3 \%$ and $44.9 \%$ presented a significant similarity for a protein with a known function; ii) $4.6 \%$ and $11.3 \%$ showed similarities for predicted proteins; iii) $18.1 \%$ and $43.8 \%$ did not returned any results; iv) GO-terms were then attributed to $52.2 \%$ and $22.3 \%$ of the transcripts; v) KEGG enzyme code was assigned to $11.3 \%$ and $5.5 \%$ of the sequences; and vi) conserved protein domains were detected in 52\% and 50.6\% of the transcript. Analysis of the RNA-seq based approached of GO-term repartition using WEGO (Ye et al. 2006) shows that our predicted transcripts enter in 6,6 and $20 \mathrm{GO}$ categories (GO level 2, for all level GO repartition, see the supplementary data 2) of the Cellular Component, Molecular Function and Biological Process root, respectively (Fig.1). For the RNA-seq based approach, orthoMCL had generated 16,469 groups of orthologs containing 47,388 transcripts (Table 3). This allowed to successfully annotating 24,024 transcripts with a high level of confidence (50.6\% of those in clusters). For the ab initio approach, 27,440 groups of orthologs were created; they contain 45,839 transcripts and enable the annotation of 25,335 sequences. In comparison to what is usually obtained in transcriptome assembly of non-model invertebrates the number of transcripts showing significant similarities for protein with a putative function is high. Indeed, this rate fluctuates in general between 20 and 50\% in many recent studies (Kitchen et al. 2015, Harney et al. 2016, McGrath et al. 2016). However in draft genome assembly this rates of annotation is higher and comparable to what we obtained (Shinzato et al. 2011, Baumgarten et al. 2015). This is probably due to a better sequencing coverage of the gene set in genome assembly rather than in transcriptome. Firstly, because genome de novo assembly need a higher sequencing coverage and secondly because in gDNA-seq the representation of each gene is theoretically equal while it is biased by the expression level in RNA-seq.

\section{Repeat content}

The process of repeat annotation shows that at least $15.28 \%$ of $P$. acuta genome is composed of repeated sequences. This value is very close to what was found in the genome of A. digitifera with $13 \%$ of repeat content (Shinzato et al. 2011) and lower than in Aiptasia sp. 
with $26 \%$ (Baumgarten et al. 2015). In total, the four main superfamily of TEs (DNA transposons, SINE-, LINE- and LTR-retrotransposons) were found (Table 4) and they represent 18 families of transposons and 19 families of retrotransposons (supplementary data 3). Among them, seven are specific to P. acuta and 30 and 20 are shared with Aiptasia sp. and A. digitifera, respectively (Fig. 2). However, their occurrence is low in comparison to what was found in the two other symbiotic anthozoa (Table 4). Indeed, if $15.28 \%$ of the genome is composed of repeated sequences, the identified repeat sequences represent only $3.23 \%$ of this $15.36 \%$. The remaining $11.98 \%$ correspond essentially to unidentified sequences $(11.37 \%)$ in addition to satellites $(0.03 \%)$, simple $(0.9 \%)$, low complexity repeats $(0.16 \%)$, and small RNA $(0.06 \%)$. This high level of unidentified repeated sequences is not an exception. For example, in the Aiptasia genome, $63 \%$ of the repeat content corresponds to a unique unknown repeat (Baumgarten et al. 2015).

\section{Heterozygosis and SNP library}

In order to evaluate the heterozygosis of the genome the reads from the SG library were re-mapped on the genome (Bowtie2) and variant were called with VarScan2. This analysis reveals the presence of 2,505,660 heterozygote single nucleotide polymorphisms (7.1 $\mathrm{SNP} / \mathrm{kb}$ ) and 321,295 indels. This level of heterozygosis in a single genome can be considered as very high even if we cannot exclude that a small proportion of these SNPs are false positive that can be due to sequencing or mapping error. However, if such a kind of data are absent from the anthozoan literature some comparisons are possible with other invertebrate phyla. In arthropods, SNP density can be as high as $16.5 \mathrm{SNP} / \mathrm{kb}$ in the butterflies from the genus Lycaeides (Gompert et al. 2010) and as low as 0.062 in the varroato-mite, Varroa destructor (Cornman et al. 2010). In these studies these results were obtained from dozen to hundreds of individuals, while in our study we have probably only one genotype per colony. This lead to believe that in the case of a populational study this density can significantly increase and reach very high values of SNP density. Alternatively, some of the polymorphism observed in our study can also be the results of intra colonial genetic variation, a phenomenon more and more observed and quantified in corals (Schweinsberg et al. 2014, Schweinsberg et al. 2015, Barfield et al. 2016) and that can be due to the accumulation of somatic mutations (Van Oppen et al. 2012) or to chimerism (Rinkevich et al. 2016).

\section{Cnidarian core proteome}


The cnidarian core proteome was identified through the orthoMCL approach and its annotation. It is composed of 1,781 orthologous group of proteins, shared between the two scleractinian corals $P$. acuta and A. digitifera, the anemone N.vectensis (actinia) each of them belonging to the anthozoa class, and H. magnipapillata from the hydrozoa class (Fig.3). The GO term repartition (GO level 2) between this cnidarian core proteome and the entire proteome content of $P$. acuta is very close (Fig. 4) reflecting the absence of large functional gain or loss.

\section{Conclusion}

The draft genome assembly provided by this study constitutes a new coral reference genome and a new resource for the scientific community interested in cnidarians genomics approach (sensus lato). This will enable the development of a large array of genome wide studies that will lead to a better understanding of coral physiology, ecology and adaptability.

\section{Availability}

The raw reads of each libraries were submitted to the NCBI Sequence Read Archive (accession numbers are: SRR4254617; SRR4254618; SRR4254619; SRR4254620) The draft genome and related annotation files can be downloaded using the following link http://ihpe.univ-perp.fr/acces-aux-donnees/

\section{Acknowledgements}

This study was supported by the Agence Nationale de la Recherche through the Program BIOADAPT (ADACNI ANR-12-ADAP-0016-03) and the French-Israeli High Council for Science and Technology (P2R n u29702YG). The facilities of the BioEnvironnement platform (Perpignan, France) and the ABiMS platform (Roscoff, France) were used for the bioinformatics and molecular biology studies, the Aquarium facilities of the UMS 2348 were used for the sample preparation. The authors are indebted to Rayan Chikhi for his advices in bioinformatic during the assembly processes and to Sebastian Schmidt-Roach for his informations about the differences between $P$. acuta and $P$. damicornis. 


\section{References}

Adams, M. D., S. E. Celniker, R. A. Holt, C. A. Evans, J. D. Gocayne, P. G. Amanatides, S. E. Scherer, P. W. Li, R. A. Hoskins, R. F. Galle, and e. al. 2000. The genome sequence of Drosophila melanogaster. Science 287:2185-2195.

Adjeroud, M., A. Guérécheau, J. Vidal-Dupiol, J. F. Flot, S. Arnaud-Haond, and F. Bonhomme. 2013. Genetic diversity, clonality and connectivity in the scleractinian coral Pocillopora damicornis: a multi-scale analysis in the South Pacific. Marine Biology.

Ashburner, M., C. A. Ball, J. A. Blake, D. Botstein, H. Butler, J. M. Cherry, A. P. Davis, K. Dolinski, S. S. Dwight, J. T. Eppig, M. A. Harris, D. P. Hill, L. Issel-Tarver, A. Kasarskis, S. Lewis, J. C. Matese, J. E. Richardson, M. Ringwald, G. M. Rubin, and G. Sherlock. 2000. Gene Ontology: tool for the unification of biology. Nat Genet 25:25-29.

Barfield, S., G. V. Aglyamova, and M. V. Matz. 2016. Evolutionary origins of germline segregation in Metazoa: evidence for a germ stem cell lineage in the coral Orbicella faveolata (Cnidaria, Anthozoa). Proceedings of the Royal Society of London B: Biological Sciences 283:2015-2128.

Baucom, R. S., J. C. Estill, C. Chaparro, N. Upshaw, A. Jogi, J.-M. Deragon, R. P. Westerman, P. J. SanMiguel, and J. L. Bennetzen. 2009. Exceptional diversity, nonrandom distribution, and rapid evolution of retroelements in the B73 maize genome. PLoS Genet 5:e1000732.

Baumgarten, S., O. Simakov, L. Y. Esherick, Y. J. Liew, E. M. Lehnert, C. T. Michell, Y. Li, E. A. Hambleton, A. Guse, M. E. Oates, J. Gough, V. M. Weis, M. Aranda, J. R. Pringle, and C. R. Voolstra. 2015. The genome of Aiptasia, a sea anemone model for coral symbiosis. Proceedings of the National Academy of Sciences of The United States Of America 112:11893-11898.

Bellwood, D. R., T. P. Hughes, C. Folke, and M. Nyström. 2004. Confronting the coral reef crisis. Nature 429:827-833.

Ben-Haim Rozenblat, Y. and E. Rosenberg 2004. Temperature-regulated bleaching and tissue lysis of Pocillopora damicornis by the novel pathogen Vibrio coralliilyticus. Pages 301-324 in E. Rosenberg and Y. Loya editors. Coral health and disease. SpingerVerlag, New-York.

Ben-Haim, Y. and E. Rosenberg. 2002. A novel Vibrio sp. pathogen of the coral Pocillopora damicornis. Marine Biology 141:47-55.

Bourne, D. G. and C. B. Munn. 2005. Diversity of bacteria associated with the coral Pocillopora damicornis from the Great Barrier Reef. Environmental Microbiology 7:1162-1174.

Bryant, D., L. Burke, J. W. McManus, and M. D. Spalding. 1998. Reefs at risk: a map based indicator of threats to the world's coral reefs., World Resources Institute, Washington, D.C.

Chapman, J. A., E. F. Kirkness, O. Simakov, S. E. Hampson, T. Mitros, T. Weinmaier, T. Rattei, P. G. Balasubramanian, J. Borman, D. Busam, K. Disbennett, C. Pfannkoch, N. Sumin, G. G. Sutton, L. D. Viswanathan, B. Walenz, D. M. Goodstein, U. Hellsten, T. Kawashima, S. E. Prochnik, N. H. Putnam, S. Shu, B. Blumberg, C. E. Dana, L. Gee, D. F. Kibler, L. Law, D. Lindgens, D. E. Martinez, J. Peng, P. A. Wigge, B. Bertulat, C. Guder, Y. Nakamura, S. Ozbek, H. Watanabe, K. Khalturin, G. Hemmrich, A. Franke, R. Augustin, S. Fraune, E. Hayakawa, S. Hayakawa, M. Hirose, J. S. Hwang, K. Ikeo, C. Nishimiya-Fujisawa, A. Ogura, T. Takahashi, P. R. H. Steinmetz, X. Zhang, R. Aufschnaiter, M.-K. Eder, A.-K. Gorny, W. Salvenmoser, A. M. Heimberg, B. M. Wheeler, K. J. Peterson, A. Bottger, P. Tischler, A. Wolf, T. Gojobori, K. A. 
Remington, R. L. Strausberg, J. C. Venter, U. Technau, B. Hobmayer, T. C. G. Bosch, T. W. Holstein, T. Fujisawa, H. R. Bode, C. N. David, D. S. Rokhsar, and R. E. Steele. 2010. The dynamic genome of Hydra. Nature 464:592-596.

Chinwalla, A. T., L. L. Cook, K. D. Delehaunty, G. A. Fewell, L. A. Fulton, R. S. Fulton, T. A. Graves, L. W. Hillier, E. R. Mardis, J. D. McPherson, and e. al. 2002. Initial sequencing and comparative analysis of the mouse genome. Nature 420:520-562.

Combosch, D. J. and S. V. Vollmer. 2015. Trans-Pacific RAD-Seq population genomics confirms introgressive hybridization in Eastern Pacific Pocillopora corals. Molecular Phylogenetics and Evolution 88:154-162.

Conesa, A., S. Götz, J. M. Garcia-Gomez, J. Terol, M. Talon, and M. Robles. 2005. Blast2GO: a universal tool for annotation, visualization and analysis in functional genomics research. Bioinformatics 21:3674-3676.

Consortium, S. 1998. Genome sequence of the nematode C. elegans: A platform for investigating biology. Science 282:2012-2018.

Cornman, R. S., M. C. Schatz, J. S. Johnston, Y.-P. Chen, J. Pettis, G. Hunt, L. Bourgeois, C. Elsik, D. Anderson, C. M. Grozinger, and J. D. Evans. 2010. Genomic survey of the ectoparasitic mite Varroa destructor, a major pest of the honey bee Apis mellifera. BMC Genomics 11:1-15.

Cunning, R., R. A. Bay, P. Gillette, A. C. Baker, and N. Traylor-Knowles. 2018. Comparative analysis of the Pocillopora damicornis genome highlights role of immune system in coral evolution. Scientific Reports 8:16134.

Done, T. J., J. C. Ogden, and W. J. Wiebe 1996. Biodiversity and ecosystem function of coral reefs. Pages 393-429 in H. A. Mooney, E. Cushman, O. E. S. Medina, and E. D. Schulze, editors. Functional role of biodiversity: A global perspective. John Wiley and Sons, Chichester.

Gompert, Z., M. L. Forister, J. A. Fordyce, C. C. Nice, R. J. Williamson, and C. Alex Buerkle. 2010. Bayesian analysis of molecular variance in pyrosequences quantifies population genetic structure across the genome of Lycaeides butterflies. Molecular Ecology 19:2455-2473.

Gurevich, A., V. Saveliev, N. Vyahhi, and G. Tesler. 2013. QUAST: quality assessment tool for genome assemblies. Bioinformatics 29:1072-1075.

Harney, E., B. Dubief, P. Boudry, O. Basuyaux, M. B. Schilhabel, S. Huchette, C. Paillard, and F. L. Nunes. 2016. De novo assembly and annotation of the European abalone Haliotis tuberculata transcriptome. Marine genomics.

Howe, K., M. D. Clark, C. F. Torroja, J. Torrance, C. Berthelot, M. Muffato, J. E. Collins, S. Humphray, K. McLaren, and L. Matthews. 2013. The zebrafish reference genome sequence and its relationship to the human genome. Nature 496:498-503.

Hughes, T., A. Baird, D. Bellwood, M. Card, S. Connolly, C. Folke, R. Grosberg, H. Guldberg, J. Jackson, J. Kleypas, J. Lough, P. Marshall, M. Nyström, S. Palumbi, J. Pandolfi, B. Rosen, and J. Roughgarden. 2003. Climate change, human impacts, and the resilience of coral reefs. Science 301:929-933.

Jurka, J., V. V. Kapitonov, A. Pavlicek, P. Klonowski, O. Kohany, and J. Walichiewicz. 2005. Repbase Update, a database of eukaryotic repetitive elements. Cytogenetic and genome research 110:462-467.

Kajitani, R., K. Toshimoto, H. Noguchi, A. Toyoda, Y. Ogura, M. Okuno, M. Yabana, M. Harada, E. Nagayasu, H. Maruyama, Y. Kohara, A. Fujiyama, T. Hayashi, and T. Itoh. 2014. Efficient de novo assembly of highly heterozygous genomes from wholegenome shotgun short reads. Genome Research.

Kanehisa, M. and S. Goto. 2000. KEGG: Kyoto Encyclopedia of Genes and Genomes. Nucleic acids research 28:27-30. 
Kitchen, S. A., C. M. Crowder, A. Z. Poole, V. M. Weis, and E. Meyer. 2015. De novo assembly and characterization of four anthozoan (phylum Cnidaria) transcriptomes. G3: Genes| Genomes| Genetics 5:2441-2452.

Knowlton, N., R. E. Brainard, R. Fisher, M. Moews, L. Plaisance, and M. J. Caley. 2010. Coral reef biodiversity. Pages 65-74 in A. D. McLntyre, editor. Life in the World's Oceans: Diversity Distribution and Abundance. Wiley-Blackwell, Singapore.

Koboldt, Daniel C., Karyn M. Steinberg, David E. Larson, Richard K. Wilson, and E. R. Mardis. 2013. The next-generation sequencing revolution and ts impact on genomics. Cell 155:27-38.

Koboldt, D. C., Q. Zhang, D. E. Larson, D. Shen, M. D. McLellan, L. Lin, C. A. Miller, E. R. Mardis, L. Ding, and R. K. Wilson. 2012. VarScan 2: Somatic mutation and copy number alteration discovery in cancer by exome sequencing. Genome Research 22:568-576.

Koch, P., M. Platzer, and B. R. Downie. 2014. RepARK - de novo creation of repeat libraries from whole-genome NGS reads. Nucleic acids research.

Langmead, B. and S. L. Salzberg. 2012. Fast gapped-read alignment with Bowtie 2. Nature Methods 9:357-359.

Lehnert, E., M. Burriesci, and J. Pringle. 2012. Developing the anemone Aiptasia as a tractable model for cnidarian-dinoflagellate symbiosis: the transcriptome of aposymbiotic A. pallida. BMC Genomics 13:271.

Li, H., B. Handsaker, A. Wysoker, T. Fennell, J. Ruan, N. Homer, G. Marth, G. Abecasis, R. Durbin, and G. P. D. P. Subgroup. 2009. The Sequence Alignment/Map format and SAMtools. Bioinformatics 25:2078-2079.

Li, L., C. J. Stoeckert, and D. S. Roos. 2003. OrthoMCL: identification of ortholog groups for eukaryotic genomes. Genome Research 13:2178-2189.

Lin, S., S. Cheng, B. Song, X. Zhong, X. Lin, W. Li, L. Li, Y. Zhang, H. Zhang, J. Zhiliang, M. Cai, Y. Zhuang, X. Shi, L. Lin, L. Wang, Z. Wang, X. Liu, S. Yu, P. Zeng, H. Hao, Q. Zou, C. Chen, Y. Li, Y. Wang, C. Xu, S. Meng, X. Xu, J. Wang, H. Yang, D. A. Campbell, N. R. Sturm, S. Dagenais-Bellefeuille, and D. Morse. 2015. The Symbiodinium kawagutii genome illuminates dinoflagellate gene expression and coral symbiosis. Science 350:691-694.

Loya, Y., K. Sakai, K. Yamazato, Y. Nakano, R. Sambali, and R. V. Van Woesik. 2001. Coral bleaching: the winners and the losers. Ecology Letters 4:122-131.

Luna, G. M., F. Biavasco, and R. Danovaro. 2007. Bacteria associated with the rapid tissue necrosis of stony corals. Environmental Microbiology 9:1851-1857.

Luo, R., B. Liu, Y. Xie, Z. Li, W. Huang, J. Yuan, G. He, Y. Chen, Q. Pan, Y. Liu, J. Tang, G. Wu, H. Zhang, Y. Shi, Y. Liu, C. Yu, B. Wang, Y. Lu, C. Han, D. Cheung, S.-M. Yiu, S. Peng, Z. Xiaoqian, G. Liu, X. Liao, Y. Li, H. Yang, J. Wang, T.-W. Lam, and J. Wang. 2012. SOAPdenovo2: an empirically improved memory-efficient short-read de novo assembler. GigaScience 1:18.

Martin, M. 2011. Cutadapt removes adapter sequences from high-throughput sequencing reads. EMBnet. journal 17:10-12.

McGrath, L. L., S. V. Vollmer, S. T. Kaluziak, and J. Ayers. 2016. De novo transcriptome assembly for the lobster Homarus americanus and characterization of differential gene expression across nervous system tissues. BMC Genomics 17:1-16.

Mewes, H., K. Albermann, M. Bähr, D. Frishman, A. Gleissner, J. Hani, K. Heumann, K. Kleine, A. Maierl, and S. Oliver. 1997. Overview of the yeast genome. Nature 387:78. 
Meyer, E., G. Aglyamova, S. Wang, J. Buchanan-Carter, D. Abrego, J. Colbourne, B. Willis, and M. Matz. 2009. Sequencing and de novo analysis of a coral larval transcriptome using 454 GSFlx. BMC Genomics 10:219.

Mofiz, E., D. C. Holt, T. Seemann, B. J. Currie, K. Fischer, and A. T. Papenfuss. 2016. Genomic resources and draft assemblies of the human and porcine varieties of scabies mites, Sarcoptes scabiei var. hominis and var. suis. GigaScience 5:1.

Moya, A., L. Huisman, E. E. Ball, D. C. Hayward, L. C. Grasso, C. M. Chua, H. N. Woo, J. P. Gattuso, S. Forêt, and D. J. Miller. 2012. Whole transcriptome analysis of the coral Acropora millepora reveals complex responses to $\mathrm{CO}_{2}$-driven acidification during the initiation of calcification. Molecular Ecology 21:2440-2454.

Parra, G., K. Bradnam, and I. Korf. 2007. CEGMA: a pipeline to accurately annotate core genes in eukaryotic genomes. Bioinformatics 23:1061-1067.

Prada, C., B. Hanna, A. F. Budd, C. M. Woodley, J. Schmutz, J. Grimwood, R. IglesiasPrieto, J. M. Pandolfi, D. Levitan, K. G. Johnson, N. Knowlton, H. Kitano, M. DeGiorgio, and M. Medina. 2016. Empty Niches after Extinctions Increase Population Sizes of Modern Corals. Current Biology 26:3190-3194.

Putnam, H. M. and R. D. Gates. 2015. Preconditioning in the reef-building coral Pocillopora damicornis and the potential for trans-generational acclimatization in coral larvae under future climate change conditions. Journal of Experimental Biology 218:23652372.

Putnam, N. H., M. Srivastava, U. Hellsten, B. Dirks, J. Chapman, A. Salamov, A. Terry, H. Shapiro, E. Lindquist, V. V. Kapitonov, J. Jurka, G. Genikhovich, I. V. Grigoriev, S. M. Lucas, R. E. Steele, J. R. Finnerty, U. Technau, M. Q. Martindale, and D. S. Rokhsar. 2007. Sea anemone genome reveals ancestral eumetazoan gene repertoire and genomic organization. Science 317:86-94.

Rice, P., I. Longden, and A. Bleasby. 2000. EMBOSS: the European molecular biology open software suite. Trends in genetics 16:276-277.

Richmond, R. H. 1987. Energetics, competency, and long-distance dispersal of planula larvae of the coral Pocillopora damicornis. Marine Biology 93:527-533.

Rinkevich, B., L. Shaish, J. Douek, and R. Ben-Shlomo. 2016. Venturing in coral larval chimerism: a compact functional domain with fostered genotypic diversity. Scientific Reports 6:19493.

Sabourault, C., P. Ganot, E. Deleury, D. Allemand, and P. Furla. 2009. Comprehensive EST analysis of the symbiotic sea anemone Anemonia viridis. BMC Genomics 10:333.

Schmidt-Roach, S., K. J. Miller, P. Lundgren, and N. Andreakis. 2014. With eyes wide open: a revision of species within and closely related to the Pocillopora damicornis species complex (Scleractinia; Pocilloporidae) using morphology and genetics. Zoological Journal of the Linnean Society 170:1-33.

Schweinsberg, M., R. G. Pech, R. Tollrian, and K. Lampert. 2014. Transfer of intracolonial genetic variability through gametes in Acropora hyacinthus corals. Coral reefs 33:7787.

Schweinsberg, M., L. C. Weiss, S. Striewski, R. Tollrian, and K. P. Lampert. 2015. More than one genotype: how common is intracolonial genetic variability in scleractinian corals? Molecular Ecology 24:2673-2685.

Shinzato, C., M. Inoue, and M. Kusakabe. 2014. A snapshot of a coral "holobiont": a transcriptome assembly of the scleractinian coral, Porites, captures a wide variety of genes from both the host and symbiotic zooxanthellae. PLoS ONE 9:e85182.

Shinzato, C., E. Shoguchi, T. Kawashima, M. Hamada, K. Hisata, M. Tanaka, M. Fujie, M. Fujiwaea, R. Koyanagi, T. Ikuta, A. Fujiyama, D. Miller, and N. Satoh. 2011. Using 
the Acropora digitifera genome to understand coral responses to environmental change. Nature 476:320-323.

Shoguchi, E., C. Shinzato, T. Kawashima, F. Gyoja, S. Mungpakdee, R. Koyanagi, T. Takeuchi, K. Hisata, M. Tanaka, M. Fujiwara, M. Hamada, A. Seidi, M. Fujie, T. Usami, H. Goto, S. Yamasaki, N. Arakaki, Y. Suzuki, S. Sugano, A. Toyoda, Y. Kuroki, A. Fujiyama, M. n. Medina, MaryÂA A. Coffroth, D. Bhattacharya, and N. Satoh. 2013. Draft assembly of the Symbiodinium minutum nuclear genome reveals dinoflagellate gene structure. Current Biology 23:1399-1408.

Smit, A. and R. Hubley. 2010. RepeatModeler Open-1.0. Repeat Masker Website.

Sodergren, E. and G. M. Weinstock and E. H. Davidson and R. A. Cameron and R. A. Gibbs and R. C. Angerer and L. M. Angerer and M. I. Arnone and D. R. Burgess and R. D. Burke and J. A. Coffman and M. Dean and M. R. Elphick and C. A. Ettensohn and K. R. Foltz and A. Hamdoun and R. O. Hynes and W. H. Klein and W. Marzluff and D. R. McClay and R. L. Morris and A. Mushegian and J. P. Rast and L. C. Smith and M. C. Thorndyke and V. D. Vacquier and G. M. Wessel and G. Wray and L. Zhang and C. G. Elsik and O. Ermolaeva and W. Hlavina and G. Hofmann and P. Kitts and M. J. Landrum and A. J. Mackey and D. Maglott and G. Panopoulou and A. J. Poustka and K. Pruitt and V. Sapojnikov and X. Song and A. Souvorov and V. Solovyev and Z. Wei and C. A. Whittaker and K. Worley and K. J. Durbin and Y. Shen and O. Fedrigo and D. Garfield and R. Haygood and A. Primus and R. Satija and T. Severson and M. L. Gonzalez-Garay and A. R. Jackson and A. Milosavljevic and M. Tong and C. E. Killian and B. T. Livingston and F. H. Wilt and N. Adams and R. Bellé and S. Carbonneau and R. Cheung and P. Cormier and B. Cosson and J. Croce and A. Fernandez-Guerra and A.-M. Genevière and M. Goel and H. Kelkar and J. Morales and O. Mulner-Lorillon and A. J. Robertson and J. V. Goldstone and B. Cole and D. Epel and B. Gold and M. E. Hahn and M. Howard-Ashby and M. Scally and J. J. Stegeman and E. L. Allgood and J. Cool and K. M. Judkins and S. S. McCafferty and A. M. Musante and R. A. Obar and A. P. Rawson and B. J. Rossetti and I. R. Gibbons and M. P. Hoffman and A. Leone and S. Istrail and S. C. Materna and M. P. Samanta and V. Stolc and W. Tongprasit and Q. Tu and K.-F. Bergeron and B. P. Brandhorst and J. Whittle and K. Berney and D. J. Bottjer and C. Calestani and K. Peterson and E. Chow and Q. A. Yuan and E. Elhaik and D. Graur and J. T. Reese and I. Bosdet and S. Heesun and M. A. Marra and J. Schein and M. K. Anderson and V. Brockton and K. M. Buckley and A. H. Cohen and S. D. Fugmann and T. Hibino and M. Loza-Coll and A. J. Majeske and C. Messier and S. V. Nair and Z. Pancer and D. P. Terwilliger and C. Agca and E. Arboleda and N. Chen and A. M. Churcher and F. Hallböök and G. W. Humphrey and M. M. Idris and T. Kiyama and S. Liang and D. Mellott and X. Mu and G. Murray and R. P. Olinski and F. Raible and M. Rowe and J. S. Taylor and K. Tessmar-Raible and D. Wang and K. H. Wilson and S. Yaguchi and T. Gaasterland and B. E. Galindo and H. J. Gunaratne and C. Juliano and M. Kinukawa and G. W. Moy and A. T. Neill and M. Nomura and M. Raisch and A. Reade and M. M. Roux and J. L. Song and Y.-H. Su and I. K. Townley and E. Voronina and J. L. Wong and G. Amore and M. Branno and E. R. Brown and V. Cavalieri and V. Duboc and L. Duloquin and C. Flytzanis and C. Gache and F. Lapraz and T. Lepage and A. Locascio and P. Martinez and G. Matassi and V. Matranga and R. Range and F. Rizzo and E. Röttinger and W. Beane and C. Bradham and C. Byrum and T. Glenn and S. Hussain and G. Manning and E. Miranda and R. Thomason and K. Walton and A. Wikramanayke and S.-Y. Wu and R. Xu and C. T. Brown and L. Chen and R. F. Gray and P. Y. Lee and J. Nam and P. Oliveri and J. Smith and D. Muzny and S. Bell and J. Chacko and A. Cree and S. Curry and C. Davis and H. Dinh and S. Dugan-Rocha and 
J. Fowler and R. Gill and C. Hamilton and J. Hernandez and S. Hines and J. Hume and L. Jackson and A. Jolivet and C. Kovar and S. Lee and L. Lewis and G. Miner and M. Morgan and L. V. Nazareth and G. Okwuonu and D. Parker and L.-L. Pu and R. Thorn and R. Wright. 2006. The genome of the sea urchin Strongylocentrotus purpuratus. Science 314:941-952.

Song, L., C. Bian, Y. Luo, L. Wang, X. You, J. Li, Y. Qiu, X. Ma, Z. Zhu, and L. Ma. 2016. Draft genome of the Chinese mitten crab, Eriocheir sinensis. GigaScience 5:1.

Srivastava, M., O. Simakov, J. Chapman, B. Fahey, M. E. A. Gauthier, T. Mitros, G. S. Richards, C. Conaco, M. Dacre, U. Hellsten, C. Larroux, N. H. Putnam, M. Stanke, M. Adamska, A. Darling, S. M. Degnan, T. H. Oakley, D. C. Plachetzki, Y. Zhai, M. Adamski, A. Calcino, S. F. Cummins, D. M. Goodstein, C. Harris, D. J. Jackson, S. P. Leys, S. Shu, B. J. Woodcroft, M. Vervoort, K. S. Kosik, G. Manning, B. M. Degnan, and D. S. Rokhsar. 2010. The Amphimedon queenslandica genome and the evolution of animal complexity. Nature 466:720-726.

Stanke, M. and S. Waack. 2003. Gene prediction with a hidden Markov model and a new intron submodel. Bioinformatics 19:ii215-ii225.

Stimson, J. 1997. The annual cycle of density of zooxanthellae in the tissues of field and laboratory-held Pocillopora damicornis (Linnaeus). Journal of Experimental Marine Biology and Ecology 214:35-48.

Tarailo-Graovac, M. and N. Chen. 2009. Using RepeatMasker to identify repetitive elements in genomic sequences. Current Protocols in Bioinformatics 25:1-14.

Trapnell, C., L. Pachter, and S. L. Salzberg. 2009. TopHat: discovering splice junctions with RNA-Seq. Bioinformatics 25:1105-1111.

Trapnell, C., B. A. Williams, G. Pertea, A. Mortazavi, G. Kwan, M. J. van Baren, S. L. Salzberg, B. J. Wold, and L. Pachter. 2010. Transcript assembly and abundance estimation from RNA-Seq reveals thousands of new transcripts and switching among isoforms. Nature Biotechnology 28:511-515.

Traylor-Knowles, N., B. Granger, T. Lubinski, J. Parikh, S. Garamszegi, Y. Xia, J. Marto, L. Kaufman, and J. Finnerty. 2011. Production of a reference transcriptome and a transcriptomic database (PocilloporaBase) for the cauliflower coral, Pocillopora damicornis. BMC Genomics 12:585.

Van Oppen, M. J. H., P. Souter, E. J. Howells, A. Heyward, and R. Berkelmans. 2012. Novel genetic diversity through somatic mutations: fuel for adaptation of reef corals? Diversity 3:405-423.

Venter, J. C. and M. D. Adams and E. W. Myers and P. W. Li and R. J. Mural and G. G. Sutton and H. O. Smith and M. Yandell and C. A. Evans and R. A. Holt and J. D. Gocayne and P. Amanatides and R. M. Ballew and D. H. Huson and J. R. Wortman and Q. Zhang and C. D. Kodira and X. H. Zheng and L. Chen and M. Skupski and G. Subramanian and P. D. Thomas and J. Zhang and G. L. Gabor Miklos and C. Nelson and S. Broder and A. G. Clark and J. Nadeau and V. A. McKusick and N. Zinder and A. J. Levine and R. J. Roberts and M. Simon and C. Slayman and M. Hunkapiller and R. Bolanos and A. Delcher and I. Dew and D. Fasulo and M. Flanigan and L. Florea and A. Halpern and S. Hannenhalli and S. Kravitz and S. Levy and C. Mobarry and K. Reinert and K. Remington and J. Abu-Threideh and E. Beasley and K. Biddick and V. Bonazzi and R. Brandon and M. Cargill and I. Chandramouliswaran and R. Charlab and K. Chaturvedi and Z. Deng and V. D. Francesco and P. Dunn and K. Eilbeck and C. Evangelista and A. E. Gabrielian and W. Gan and W. Ge and F. Gong and Z. Gu and P. Guan and T. J. Heiman and M. E. Higgins and R.-R. Ji and Z. Ke and K. A. Ketchum and Z. Lai and Y. Lei and Z. Li and J. Li and Y. Liang and X. Lin and F. Lu and G. V. Merkulov and N. Milshina and H. M. Moore and A. K. Naik and V. A. 
Narayan and B. Neelam and D. Nusskern and D. B. Rusch and S. Salzberg and W. Shao and B. Shue and J. Sun and Z. Y. Wang and A. Wang and X. Wang and J. Wang and M.-H. Wei and R. Wides and C. Xiao and C. Yan and A. Yao and J. Ye and M. Zhan and W. Zhang and H. Zhang and Q. Zhao and L. Zheng and F. Zhong and W. Zhong and S. C. Zhu and S. Zhao and D. Gilbert and S. Baumhueter and G. Spier and C. Carter and A. Cravchik and T. Woodage and F. Ali and H. An and A. Awe and D. Baldwin and H. Baden and M. Barnstead and I. Barrow and K. Beeson and D. Busam and A. Carver and A. Center and M. L. Cheng and L. Curry and S. Danaher and L. Davenport and R. Desilets and S. Dietz and K. Dodson and L. Doup and S. Ferriera and N. Garg and A. Gluecksmann and B. Hart and J. Haynes and C. Haynes and C. Heiner and S. Hladun and D. Hostin and J. Houck and T. Howland and C. Ibegwam and J. Johnson and F. Kalush and L. Kline and S. Koduru and A. Love and F. Mann and D. May and S. McCawley and T. McIntosh and I. McMullen and M. Moy and L. Moy and B. Murphy and K. Nelson and C. Pfannkoch and E. Pratts and V. Puri and H. Qureshi and M. Reardon and R. Rodriguez and Y.-H. Rogers and D. Romblad and B. Ruhfel and R. Scott and C. Sitter and M. Smallwood and E. Stewart and R. Strong and E. Suh and R. Thomas and N. N. Tint and S. Tse and C. Vech and G. Wang and J. Wetter and S. Williams and M. Williams and S. Windsor and E. Winn-Deen and K. Wolfe and J. Zaveri and K. Zaveri and J. F. Abril and R. Guigó and M. J. Campbell and K. V. Sjolander and B. Karlak and A. Kejariwal and H. Mi and B. Lazareva and T. Hatton and A. Narechania and K. Diemer and A. Muruganujan and N. Guo and S. Sato and V. Bafna and S. Istrail and R. Lippert and R. Schwartz and B. Walenz and S. Yooseph and D. Allen and A. Basu and J. Baxendale and L. Blick and M. Caminha and J. Carnes-Stine and P. Caulk and Y.-H. Chiang and M. Coyne and C. Dahlke and A. D. Mays and M. Dombroski and M. Donnelly and D. Ely and S. Esparham and C. Fosler and H. Gire and S. Glanowski and K. Glasser and A. Glodek and M. Gorokhov and K. Graham and B. Gropman and M. Harris and J. Heil and S. Henderson and J. Hoover and D. Jennings and C. Jordan and J. Jordan and J. Kasha and L. Kagan and C. Kraft and A. Levitsky and M. Lewis and X. Liu and J. Lopez and D. Ma and W. Majoros and J. McDaniel and S. Murphy and M. Newman and T. Nguyen and N. Nguyen and M. Nodell and S. Pan and J. Peck and M. Peterson and W. Rowe and R. Sanders and J. Scott and M. Simpson and T. Smith and A. Sprague and T. Stockwell and R. Turner and E. Venter and M. Wang and M. Wen and D. Wu and M. Wu and A. Xia and A. Zandieh and X. Zhu. 2001. The sequence of the human genome. Science 291:1304-1351.

Veron, J. E. N. 2000. Corals of the World. Australian Institute of Marine Science, Townsville.

Veron, J. E. N. and M. Pichon. 1976. Scleractinia of eastern Australia, Part I. Families Thamnasteriidae, Astrocoeniidae, Pocilloporidae.

Vidal-Dupiol, J., M. Adjeroud, E. Roger, L. Foure, D. Duval, Y. Mone, C. Ferrier-Pages, E. Tambutte, S. Tambutte, D. Zoccola, D. Allemand, and G. Mitta. 2009. Coral bleaching under thermal stress: putative involvement of host/symbiont recognition mechanisms. BMC Physiology 9:14.

Vidal-Dupiol, J., N. M. Dheilly, R. Rondon, C. Grunau, C. Cosseau, K. M. Smith, M. Freitag, M. Adjeroud, and G. Mitta. 2014. Thermal stress triggers broad Pocillopora damicornis transcriptomic remodeling, while Vibrio coralliilyticus infection induces a more targeted immuno-suppression response. PLoS ONE 9:e107672.

Vidal-Dupiol, J., O. Ladrière, D. Destoumieux-Garzon, P.-E. Sautière, A. L. Meistertzheim, E. Tambutté, S. Tambutté, D. Duval, L. Fouré, M. Adjeroud, and G. Mitta. 2011a. Innate immune responses of a scleractinian coral to vibriosis. The Journal of Biological Chemistry 286:22688-22698. 
Vidal-Dupiol, J., O. Ladrière, A. L. Meistertzheim, L. Fouré, M. Adjeroud, and G. Mitta. 2011b. Physiological responses of the scleractinian coral Pocillopora damicornis to bacterial stress from Vibrio coralliilyticus. The Journal of Experimental Biology 214:1533-1545.

Vidal-Dupiol, J., E. Toulza, O. Rey, D. Roquis, C. Chaparro, C. Cosseau, A. Picart-Picolo, P. Romans, M. Pratlong, K. Brener-Raffalli, P. Pontaroti, M. Adjeroud, G. Mitta, and C. Grunau. submitted. Genetic and epigenetic changes mediate rapid adaptation to global warming in a tropical coral

Vidal-Dupiol, J., D. Zoccola, E. Tambutté, C. Grunau, C. Cosseau, K. M. Smith, M. Freitag, N. M. Dheilly, D. Allemand, and S. Tambutté. 2013. Genes related to ion-transport and energy production are upregulated in response to $\mathrm{CO}_{2}$-driven $\mathrm{pH}$ decrease in corals: New insights from transcriptome analysis. PLoS ONE 8:e58652.

Voolstra, C. R., Y. Li, Y. J. Liew, S. Baumgarten, D. Zoccola, J.-F. Flot, S. Tambutté, D. Allemand, and M. Aranda. 2017. Comparative analysis of the genomes of Stylophora pistillata and Acropora digitifera provides evidence for extensive differences between species of corals. Scientific Reports 7:17583-17583.

Wang, J.-T., Y.-Y. Chen, K. S. Tew, P.-J. Meng, and C. A. Chen. 2012. Physiological and biochemical performances of menthol-induced aposymbiotic corals. PLoS ONE 7:e46406.

Ye, J., L. Fang, H. Zheng, Y. Zhang, J. Chen, Z. Zhang, J. Wang, S. Li, R. Li, L. Bolund, and J. Wang. 2006. WEGO: a web tool for plotting GO annotations. Nucleic acids research 34:W293-W297. 
Table 1: Data used for assembly

\begin{tabular}{|l|l|l|l|l|l|l|}
\hline Library & $\begin{array}{l}\text { Average insert size } \\
(\text { measured; bp) }\end{array}$ & $\begin{array}{l}\text { Paired-reads } \\
(\text { million })\end{array}$ & $\begin{array}{l}\text { Yield } \\
(\mathrm{Mb})\end{array}$ & $\begin{array}{l}\text { Genome } \\
\text { coverage* }\end{array}$ & Average Q & Q>30( \%) \\
\hline Shot-gun & 178 & 238 & 47,517 & 146 & 36.45 & 93.71 \\
\hline LJD 3Kb & 2,479 & 109 & 21,848 & 67 & 32.31 & 81.79 \\
\hline LJD 8Kb & 7,825 & 44 & 8,880 & 27 & 31.98 & 80.56 \\
\hline LJD 20 Kb & 32,325 & 100 & 19,963 & 61 & 30.78 & 77.73 \\
\hline
\end{tabular}

*For an estimated (kmer distribution) genome size of $325 \mathrm{Mb}$ 
Table 2: Assembly statistics; all statistics are based on sequence of size $\geq 500 \mathrm{bp}$, unless otherwise noted

\begin{tabular}{|c|c|c|}
\hline Statistics & Contigs & Scaffolds \\
\hline Number (seq $\geq 0$ bp) & 196,891 & 168,465 \\
\hline Number $(\mathrm{seq} \geq 500 \mathrm{bp})$ & 81,286 & 58,326 \\
\hline Number (seq $\geq 1000$ bp) & 47,580 & 25,553 \\
\hline Assembly length $b p(s e q \geq 0 b p)$ & $336,691,489$ & $352,019,984$ \\
\hline Assembly length bp (seq $\geq 500 b p)$ & 309,335452 & $325,576,138$ \\
\hline Assembly length bp (seq $\geq 1000 b p)$ & $285,593,703$ & 302,677350 \\
\hline Largest & 112,653 & $1,296,445$ \\
\hline N50 & 11,125 & 171,375 \\
\hline NG50* & 10,244 & 171,375 \\
\hline N75 & 3,847 & 16,625 \\
\hline NG75* & 2,912 & 16,732 \\
\hline N90 & 1,120 & 696 \\
\hline NG90* & 818 & 521 \\
\hline Number of N's per $100 \mathrm{kbp}$ & 1.69 & 4697.98 \\
\hline $\begin{array}{l}\% \text { Core eukaryotic genes (full } \\
\text { lenght) }\end{array}$ & Not done & 84.3 \\
\hline$\%$ Core eukaryotic genes (partial) & Not done & 93.15 \\
\hline GC\% & \multicolumn{2}{|c|}{$37.84 \%$} \\
\hline
\end{tabular}

*based on the predicted genome size: $325 \mathrm{Mb}$ 
Table 3: Structural and functional annotation summary results

\begin{tabular}{|l|c|c|}
\hline & Experimental approach & Ab initio approach* \\
\hline Number of predicted gene & 36,140 & 64,558 \\
\hline Number of predicted transcript & 63,181 & 79,506 \\
\hline Mean exon length (pb) & 394 & 184 \\
\hline Mean intron length (pb) & 675 & 522 \\
\hline Transcript with functional annotation & 48,987 & 35,726 \\
\hline Matching to predicted or hypothetical protein & 2,986 & 9,004 \\
\hline No results & 11,508 & 34,776 \\
\hline With GO terms & 32,986 & 17,754 \\
\hline With Enzyme code & 7,147 & 4,389 \\
\hline With a conserved protein domain & 33,002 & 40,240 \\
\hline Transcript in an orthologs group & 47,402 & 45,839 \\
\hline Number of orthologs group & 16,469 & 27,440 \\
\hline Ortholog group with a annotation & 9,916 & 12,132 \\
\hline Transcript in an annotated orthologs group & 24,024 & 25,335 \\
\hline
\end{tabular}

*Include the sequences predicted by the experimental approach 
Table 4: Pocillopora acuta, repeat content

\begin{tabular}{|l|c|c|c|}
\hline Element (super family) & Number of occurrence & $\begin{array}{l}\text { Number of bp } \\
\text { covered }\end{array}$ & $\begin{array}{l}\text { Per cent of genome } \\
\text { coverage }\end{array}$ \\
\hline DNA transposon & 27,081 & $3,708,267$ & $1.05 \%$ \\
\hline SINE retrotransposon & 8,504 & $11,051,79$ & $0.31 \%$ \\
\hline LINE retrotransposon & 45,381 & $4,352,179$ & $1.24 \%$ \\
\hline LTR retrotransposon & 3,457 & 838,736 & $0.24 \%$ \\
\hline Unclassified & 364,626 & $40,009,286$ & $11.37 \%$ \\
\hline Small RNA & 2,751 & 198,347 & $0.06 \%$ \\
\hline Satellites & 463 & 105,608 & $0.03 \%$ \\
\hline Simple repeats & 62,511 & $3,182,003$ & $0.90 \%$ \\
\hline Low complexity & 11,794 & 576,390 & $0.16 \%$ \\
\hline
\end{tabular}


Figure legends

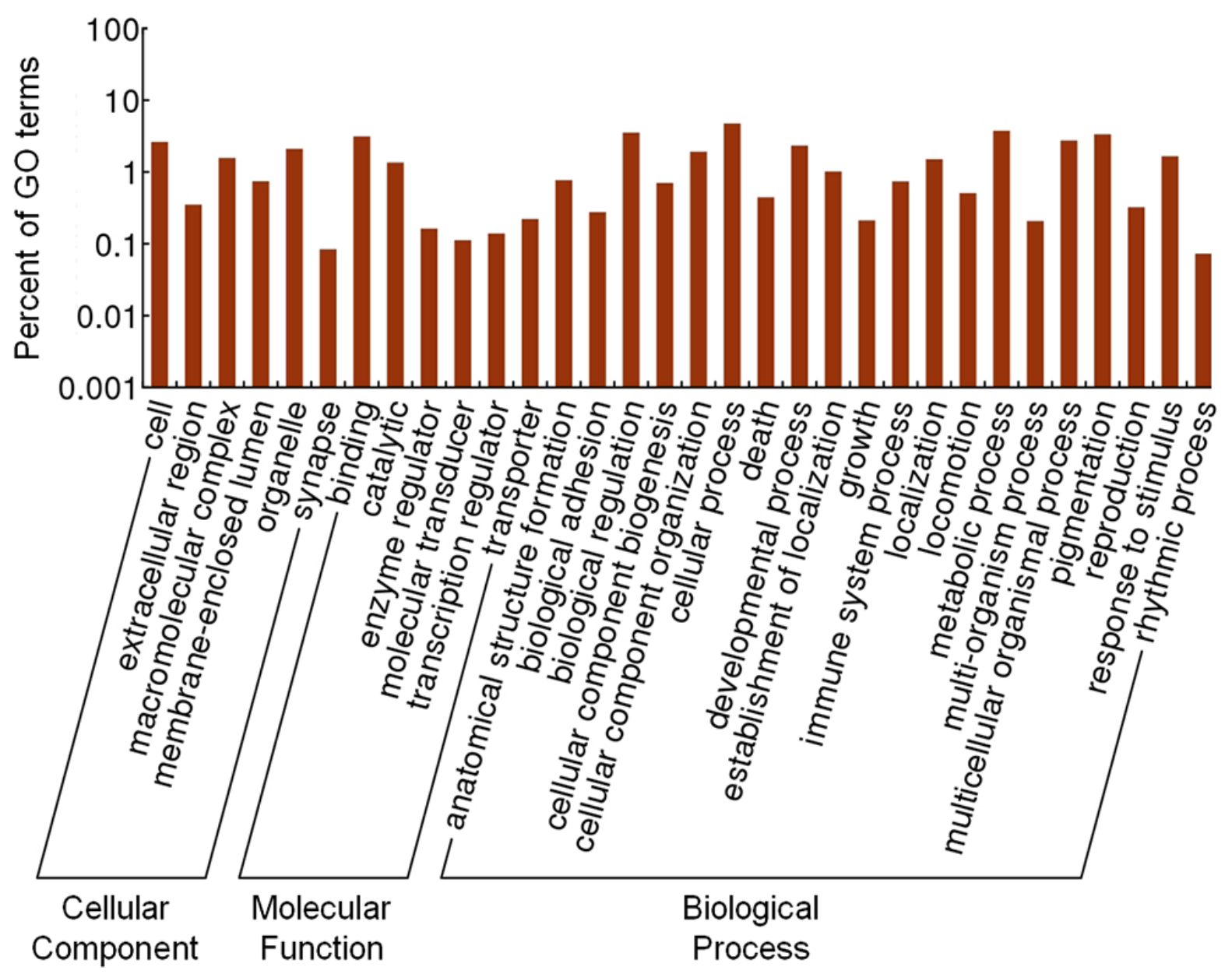

Figure 1: Distribution of GO terms belonging to the level 2 of the GO arborescence in the three main GO categories: Cellular Component, Molecular Function and Biological Process. Transcripts from the experimental annotation. 


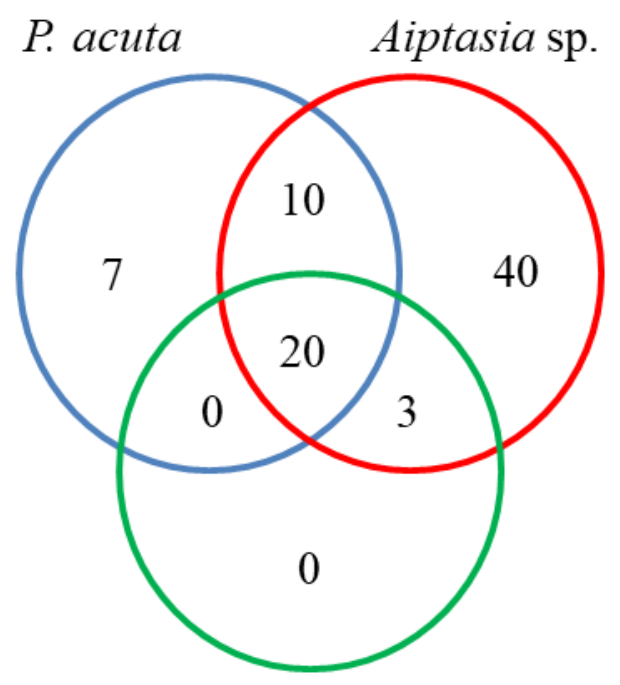

A. digitifera

Figure 2: Venn diagram representing the number of transposable elements specific or shared between the three sequenced symbiotic anthozoa, the scleractinian corals Acropora digitifera and Pocillopora acuta and the anemonia Aiptasia sp. Transposable elements for A. digitifera and Aiptasia sp. were obtained from ${ }^{8,9}$. 


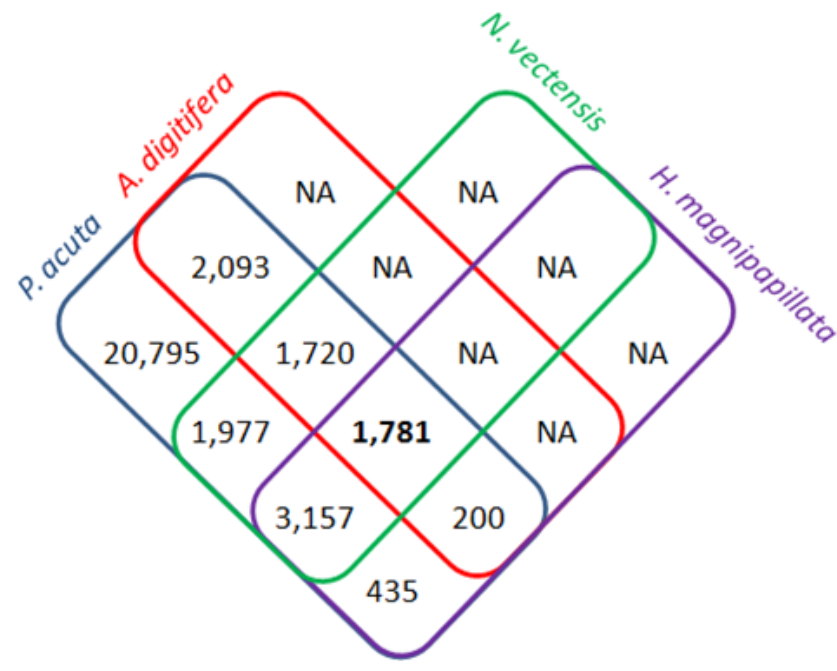

Figure 3: The cnidarian core proteome. This diagram represent the comparison between the protein content encoded in the genome of $P$. acuta and those of three other cnidarians: another scleractinia A digitifera; an actinia N. vectensis; and a hydrozoa H. magnipapillata. OrthoMCL was used to identify orthologous sequences between the predicted ORF (longer than 100AA) translated from the RNA-seq annotation and those annotated in these other genomes. The values in the diagram represent the number of group of orthologs created by orthoMCL (a group contains at least 2 sequences where at least one belongs to P. acuta). The value corresponding to the proteome restricted to $P$. acuta is composed by the number of ortholog groups containing P. acuta sequences only, plus the number of orphan sequences (sequences that are not included in a group). In total, this analysis include the 63,181 (47,402 are included in a group of ortholog, 15,779 are orphans) translated protein sequences annotated by RNA-seq in P. acuta, and 11,369, 10,636 and 7,278 sequences for A digitifera, $N$. vectensis and H. magnipapillata, respectively. NA signify not applicable: these values were not determined by this approach since the clustering was done to classify and annotate the proteome of P. acuta. Therefore, the proteins belonging to the other species and that do not has an ortholog in the genome of $P$. acuta could not be included in a ortholog group and so could not be taken into account by the analysis. 


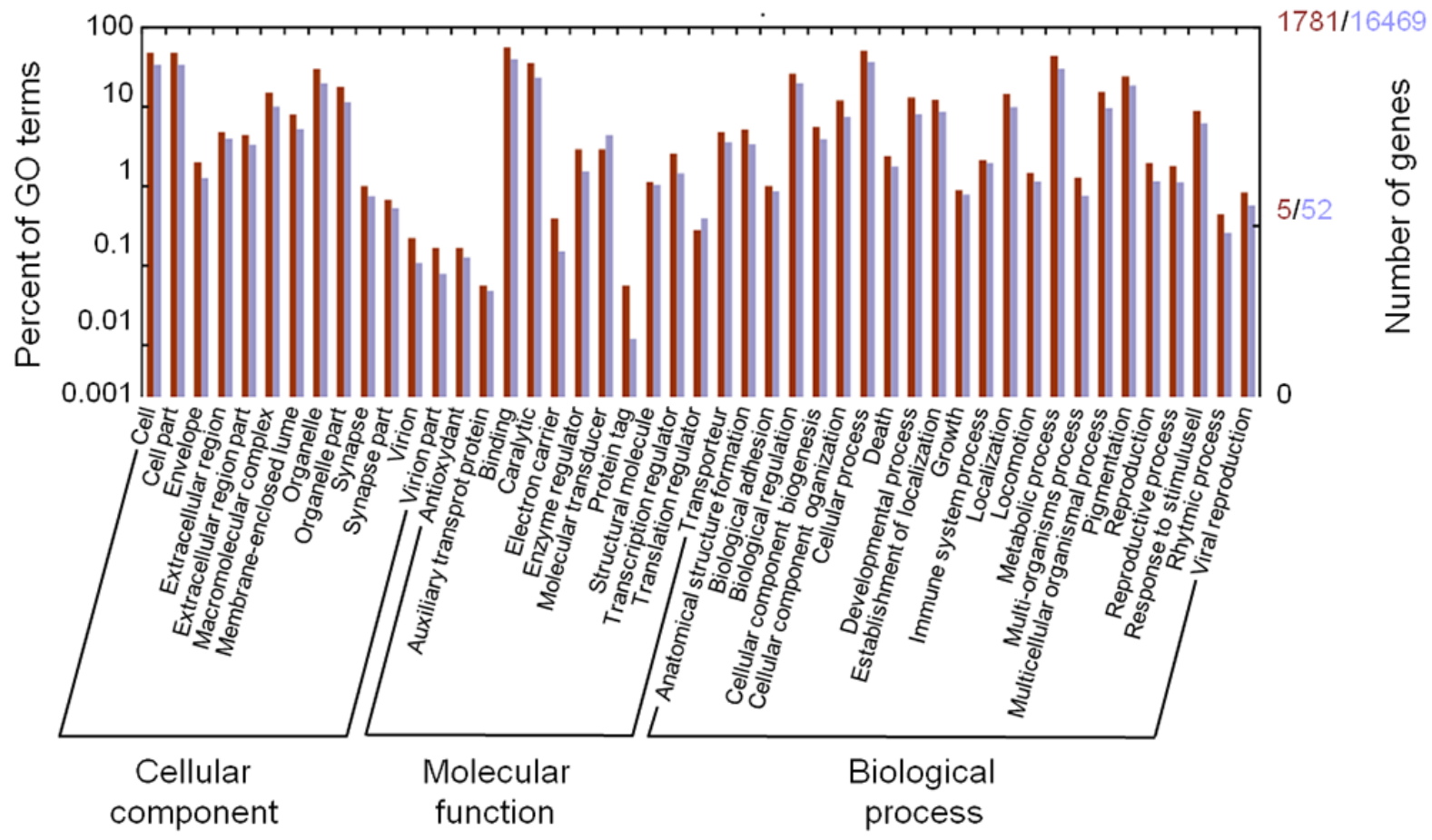

Figure 4: Distribution and comparison of GO terms included in the cnidarian core proteome (red) and the P. acuta proteome (blue). This GO terms belong to the level 2 of the GO arborescence and represent the three main GO categories: Cellular Component, Molecular Function and Biological Process. Transcripts from the experimental annotation. 